\title{
GÊNESE DO DIREITO DO VOTO FEMININO NO BRASIL: UMA ANÁLISE JURÍDICA, POLÍTICA E EDUCACIONAL ${ }^{1}$
}

\author{
Erivaldo Moreira Barbosa ${ }^{2}$ \\ Universidade Federal de Campina Grande - UFCG \\ Charliton José dos Santos Machado ${ }^{3}$ \\ Universidade Federal da Paraíba - UFPB
}

\section{RESUMO}

O presente trabalho traz como proposta investigar a gênese do direito do voto feminino no Brasil. Assim, por meio das lentes juristas e político-sociológicas, se busca mostrar como as lutas feministas por espaço no cenário público se valeram do direito, da educação e da imprensa. Destarte, fontes constitucionais, institucionais e literárias foram consultadas. Teorias biológicas, feministas, jurídicas e argumentações foram esgarçadas com o intuito de fazer cumprir os objetivos propostos. Acostado na metodologia da hermenêutica jurídico-compreensiva teve-se o desiderato de captar o movimento da vertente do "feminismo bem comportado" e da Federação Brasileira para o Progresso Feminino, relacionando-os com os seus pressupostos, o positivismo e o progresso, bem como com suas estratégias, a educação e a imprensa, além de jungi-lo com o Direito em seu duplo movimento (histórico e positivo). Percebe-se então que houve equívoco na interpretação jurídico-eleitoral, pois a Constituição Federal de 1891 não proibia expressamente as mulheres acima de 21 anos, alfabetizadas de votarem. Em conclusão, arremata-se que o Direito (histórico e positivo) serviu não como fim, mas como um dos elos fundamentais rumo ao sufrágio feminino.

Palavras-chave: Voto feminino; Direito; Política; Educação.

\section{THE ORIGIN OF THE SUFFRAGE RIGHT FOR WOMEN IN BRAZIL: A JURIDICAL, POLITICAL AND EDUCATIONAL ANALYSIS}

\begin{abstract}
This current work proposes to investigate the origin of the women's suffrage rights in Brazil. Therefore, we intend to show how the feminists struggles for space in the public scenario were based on Law, Education and the Press through juridical, political and sociological perspectives. Thus, constitutional, institutional and literacy were examined. Biological, feminists and juridical theories as well as arguments were researched in order to be possible to comply with the proposal goals. Based on a legal and comprehensive hermeneutic methodology it is intended to understand the movement that influenced the "well-behaved feminism" and also the Brazilian Federation for the women's progress, relating them to their assumptions, to the positivism, to the Progress, as well as to their strategies, to Education and to the Press, and also to Law in its double movement (historical and positivist). We realized that there was a misinterpretation of the juridical and electoral content considering that the Federal Constitution of 1891 did not prohibit the literate women over 21 years old to vote. In short, we could say that the Law (historical and positivist) was not used as a final goal, but as a fundamental link that led to women's suffrage.
\end{abstract}

Keywords: Women’s suffrage; Law; Politics; Education. 


\section{Introdução}

O artigo em foco, ancorado ao Grupo de Estudos e Pesquisas "História, Sociedade e Educação no Brasil" - (HISTEDBR-GT/PB), do Programa de Pós-Graduação em Educação - PPGE, da Universidade Federal da Paraíba, como parte das atividades desenvolvidas no âmbito do Pós-Doutorado, propõe-se analisar a gênese do voto feminino no Brasil, no lapso temporal - final do século XIX ao início dos anos 30, do século XX.

Não é comum, juristas e sociólogos brasileiros se debruçarem ao mesmo tempo sobre o direito do voto feminino no Brasil, com o intuito de esgarçarem as teorias e argumentações que a temática comporta. Porém, é admissível que o Direito Político cumpra uma das suas atribuições, qual seja, funcionar como direito fundamental da pessoa humana e dar sua contribuição ao saber, esmiuçando o assunto, o direito das mulheres de votar (capacidade eleitoral ativa) e de serem votadas (capacidade eleitoral passiva). As duas espécies de capacidades perfazem o sufrágio.

As fontes de pesquisa se resumem na Carta Constitucional de 1891, Título IV, Secção I, que traz à colação a expressão "Das Qualidades do Cidadão Brasileiro", e nas obras de pesquisadoras(es) que debatem teorias e conceitos acerca da temática esposada.

O objetivo é partir da hermenêutica jurídico-compreensiva e interpretar o conceito do Direito em seu duplo movimento (positivo e histórico) com o intuito de mostrar sua inserção nas lutas das mulheres sufragistas. Por conseguinte, busca-se deslindar a essência das teorias feministas e jurídicas, mostrando suas relações subjacentes. Daí em diante, fazse uma visita ao binômio educação/imprensa com o escopo de captar as estratégias do movimento feminista na luta pelo direito de votar. Após esse percurso, interpreta-se a Constituição Federal de 1891, a partir do seu preâmbulo que incorpora o conceito de democracia, enveredando progressivamente ao cerne da matéria eleitoral envolvente. Esgota-se no interpretar a Federação Brasileira para o Progresso Feminino, planejada na seara da vertente "feminista bem comportada".

Atente-se, que o trajeto metodológico desta pesquisa não é linear nem trilha em um único sentido, pois às vezes se distancia das teses feministas e em outros instantes corrobora com as argumentações levantadas por suas seguidoras. Este trabalho adquire um panorama diferenciado porque foi produzido pelas lentes juristas e sociológicas, muito embora se reconheça e seja irradiado por meio dos escritos literários e acadêmicos das feministas no desvendar do tema investigado.

Diante do exposto, há de se perguntar: quais as relações emergentes no discurso do voto feminino no Brasil? Qual o real significado do Direito nesse processo históricoeleitoral? Quais as informações jurídicas subjacentes que impactam e modificam as interpretações sobre o voto feminino?

Esse encadeamento de indagações estimula o Direito Político de cumprir sua função social e ao mesmo tempo de contribuir com a supressão de uma lacuna na construção do saber epistemológico sufragista feminino. Assim, o evolver da pesquisa caminhará neste compasso incomum, complexo e prazeroso.

\section{O direito como elemento contributivo ao voto feminino}

É forçoso mostrar que o Direito não deve ser visto apenas por meio da vertente positivista, como um conjunto de normas jurídicas aplicadas no tempo e espaço. O direito pode ser compreendido no bojo de um processo histórico. Conforme retrata Ihering (1991), A Luta pelo Direito, "[...] a paz é o fim que o direito tem em vista, a luta é o meio de que se serve para o conseguir". Ainda com o autor, "[...] a vida do direito é uma luta: luta dos 
povos, do Estado, das classes, dos indivíduos". Assim, arremata que "[...] o direito não é uma pura teoria, mas uma força viva" (IHERING, 1999, p.1).

Reale (1996) apresenta uma Teoria Tridimensional do Direito, conformada por três dimensões: a norma, vista como ordem; o fato, no qual o Direito se realiza na sociedade por meio da história, e o valor, quando o Direito almeja a justiça. Essa tríade permite um dinamismo ao Direito permitindo que os intérpretes possam se descolar do direito visto simplesmente como norma jurídica.

Jungindo o Direito compreendido por Ihering ao Direito teorizado por Reale, tornase possível migrar de um Direito posto para outro direito pressuposto, conforme lições de Grau (1996).

É bem verdade que o Direito não serviu como um instrumento finalístico imprescindível ao alcance das conquistas políticas feministas, porém, foi um elo fundamental no processo do voto das mulheres. De forma paradoxal, o direito positivo (posto) era um obstáculo às mudanças exigidas pelas mulheres dos finais do século XIX e primeiras décadas do século XX; por outro lado, ao mesmo tempo o direito histórico (pressuposto) emergia como dimensão contributiva à capacidade eleitoral ativa das mulheres brasileiras.

\section{“Teoria” da Incapacidade da Mulher, Teorias Feministas e Teorias Jurídicas}

São inúmeras as teorias que envolvem as múltiplas relações femininas e o sufrágio. Os percursos a serem seguidos, sobre a história e teorias, não são de "[...] biografias, de vida de mulheres específicas, mas das mulheres em seu conjunto" (...) (PERROT, 2008, p. 13). A seguir, serão abordadas as seguintes modalidades: a teoria da incapacidade da mulher, as teorias feministas e as teorias jurídicas.

A teoria da incapacidade da mulher apregoava que as mulheres eram emotivas e instáveis, e sob pressão pública não conseguiam tomar decisões racionais. Esta teoria supunha que a inaptidão feminina na esfera pública era natural e não cultural ou social. Reforçava, então, que as mulheres eram inferiores aos homens, pois tomava como base princípios formulados no âmbito interpretativo masculino.

Montagu, na obra A Superioridade Natural da Mulher, nos mostra como essa teoria se engendrou. Neste compasso, apresenta uma tabela (MONTAGU, 1970, p.31-32) composta por diferenças biológicas entre os sexos, a expressão funcional e as consequências sociais. Os homens, ao listarem os atributos biológicos masculinos como superiores e mais fortes, advogavam a tese da incapacidade cultural das mulheres e lhes inferiorizavam nas esferas públicas e sociais.

Barreto, em seu $2^{\circ}$ discurso sobre a Educação da Mulher (apud, RODRIGUES, 1993), tratou da emancipação civil e social. Demonstrou, pois, que as mulheres não eram incapazes e começou a desmontar os argumentos das suas inferioridades fisiológicas e anatômicas. Apesar da sua avançada visão desconstrutiva da teoria da incapacidade biológica da mulher, Barreto não comungava com a emancipação política feminina.

A teoria da incapacidade da mulher vigorou até início do século $\mathrm{XX}$, daí em diante foi sofrendo fissuras e perdeu força, devido em grande parte às argumentações oriundas da ciência.

As feministas brasileiras, já de posse do conhecimento científico, ajuntaram outras argumentações do campo social e cultural ao seu modelo teórico de explicação da luta pelo voto. Após decomporem os significados da ciência positivista, agregaram outros caracteres retirados do campo educacional e da imprensa. 
As feministas defendiam a tese da emancipação da mulher ou apenas uma emancipação parcial (relativa). As mulheres brasileiras que lutavam por mais espaço no mundo público não formularam uma teoria homogênea com face única, mas sim vertentes teóricas de múltiplos significados. As mulheres mais influentes, que tinham mais prestígio econômico e social, se contentaram com a luta pelo sufrágio feminino, isto é, capacidade de votar (capacidade eleitoral ativa) e capacidade de ser eleita (capacidade eleitoral passiva). Outras características da emancipação não foram objeto de luta, uma vez que somente no plano formal figuravam como reivindicação feminista.

Indaga-se então: como a educação e a imprensa serviam aos interesses das mulheres brasileiras e foram inseridas nas teorias feministas?

Um recorte do livro de Hahner, Emancipação do Sexo Feminino: a luta pelos direitos da mulher no Brasil, 1850 - 1940 (2003), responde em parte ao questionamento proposto. As primeiras defensoras dos direitos da mulher no Brasil vislumbraram que a educação era o caminho para a emancipação feminina. Assim, acostada ao pensamento positivista e o seu corolário, o progresso, potencializam as feministas a "pressionarem" os formuladores de leis ao direito à educação. Por intermédio da imprensa, as mulheres reivindicam seus interesses educacionais, mesmo sabendo que teriam uma educação inicial frágil, uma vez que apenas os conhecimentos básicos eram recebidos. Leia-se a seguir um trecho da autora supracitada, in verbis:

A educação das mulheres concentrava-se na preparação para o seu destino último: esposas e mães. Mesmo os homens brasileiros que se consideravam progressistas e que aprovavam a 'igualdade universal proclamada pelo Cristianismo', acreditavam que o objetivo da educação feminina era a preparação para a maternidade. Basicamente, as meninas deveriam aprender a cuidar bem de suas casas, pois lhes cabia a obrigação de garantir a felicidade dos homens. Todavia, alguma educação era bem acolhida, pois se tornariam melhores mães para os filhos e melhores companheiras para os maridos. Embora o homem tradicional e progressista assumissem juntos que as mulheres pertenciam ao lar, o segundo admitia ampliar o papel da mulher na família, enfatizando-lhe o poder de orientar moralmente suas crianças e fornecer bons cidadãos ao país. (HAHNER, 2003, p. 123-124).

Muito embora em 1879 ter sido criadas instituições de ensino superior para mulheres no Brasil, somente uma pequena parcela conseguiu se graduar, em face do preconceito social e da falta de recursos financeiros para custear o ensino secundário (HAHNER, 2003).

Diante do exposto, percebe-se que a educação era precária e não resolvia, por si só, a participação da mulher no sufrágio brasileiro, mas abria pequenas fendas na teoria da incapacidade da mulher. Frise-se, pois, que as mulheres acostadas ao pensamento positivista/progressista eram conscientes dessa frágil e parcial "vitória" educacional em prol do direito de votar e ser votada (sufrágio feminino).

Nesse ínterim, surgiram teses feministas contrárias a esse caminhar. Entretanto, não desconsideraram a estratégia utilizada por essas mulheres privilegiadas sócioeconomicamente de se valerem da educação e da imprensa como meios para alcançar os direitos políticos. Em resumo, os grupos divergentes (mais radicais) no seio feminista adotaram a mesma estratégia manipulando o binômio educação/imprensa como veículo de disseminação e amplitude do seu ideário, para além do sufrágio feminino. 
As duas vertentes feministas, as radicais e as bem comportadas, valiam-se dos jornais de grande circulação, bem como de jornais especializados em assuntos femininos, para ampliar suas ideias e seus projetos na busca dos direitos políticos. As feministas escreveram inúmeros artigos em jornais na defesa do sufrágio das mulheres no Brasil. A vertente feminista denominada de feminismo bem comportado, no dizer de Pinto (2003) foi limitada, pois não alcançou a emancipação total da mulher. Eis uma pergunta: quais eram as reais intenções desse grupo de mulheres? Como romper com séculos de opressão masculina? Uma luta desigual não deverá ser vencida por etapas?

Realmente corroboramos com o externar de Pinto (2003), isto porque a expressão emancipar é de magnitude superior à expressão sufrágio feminino. Emancipar é tornar-se livre, libertar-se; enquanto que sufrágio universal é o direito de votar e ser votada. Em síntese, não basta votar e ser eleita para a mulher alcançar a esfera pública em sua plenitude, pois essa conquista é apenas uma das etapas de um fenômeno mais amplo. Dito de outra forma, emancipar é ser livre em todos os sentidos; é poder se escolarizar e trabalhar nas mesmas condições de igualdade com os homens; é poder trilhar por caminhos próprios, ser plenamente capaz (de fato e de direito); é poder escolher entre ser ou não ser mãe e esposa; é partilhar direitos e deveres com os homens nas mesmas condições, sem o estigma do preconceito.

Por outro lado, o feminismo bem comportado, além de se valer do binômio educação/imprensa, também se utilizou do Direito, em suas duas faces: incorporou em parte o direito positivo (legislado) imposto pelos homens, e o direito histórico determinado por lutas ocorrentes na sociedade.

Este feminismo aceitou o direito positivo, na medida em que essa face do direito, por ser um Direito estatal, exigia ritos e condutas predeterminadas, inclusive valia-se da força quando não respeitado. Atestou-se essa afirmação no momento em que o feminismo bem comportado se utilizou das dependências da Ordem dos Advogados do Brasil - $\mathrm{OAB}^{4}$ para promover suas reuniões, bem como quando solicitou os serviços advocatícios ${ }^{5}$ para peticionar e objetar teses masculinas contrárias ao sufrágio feminino. Esta vertente do feminismo se beneficiou do direito histórico (consciente ou inconsciente), quando propugnou pelo sufrágio das mulheres. Os textos veiculados na imprensa jornalística, os inúmeros contatos com parlamentares e/ou chefes do executivo, além da arregimentação de outras mulheres por intermédio de matérias jornalísticas ou informações individuais "bocaboca" e passeatas, ainda que tímidas, foram manifestações de lutas; lutas para atingir objetivos, lutas de mulheres na reivindicação de seus direitos políticos, direitos esses que não estavam assentados, pois careciam inexoravelmente de conflitos para emergirem no seio social. Somente após essas aparições do Direito histórico sobreveio o Direito positivo (escrito pelos homens).

Em resumo, a vertente do feminismo bem comportado cumpriu o seu papel, nos limites estritamente propostos desde o seu nascedouro. Não foi além nem aquém do planejado. Atingiu seu ápice no momento da promulgação do Texto Constitucional de 1934 e, posteriormente, foi totalmente desmantelado.

\section{Constituição Federal de 1891: por uma interpretação democrática do direito feminino de votar}

O Documento principal de um país denomina-se de Constituição. Esta se perfaz com elementos normativos, axiológicos (valores) e fáticos (sociais, econômicos, políticos, religiosos) por meio de processos históricos. As componentes anteriormente descritas devem ser captadas pelo legislador constituinte de forma alargada e interpretada pelos 
julgadores de forma democrática. Dos diversos Textos Pátrios (total de sete) interpreta-se-á o de 1891, na busca de alcançar o sentido da Carta, referente ao sufrágio feminino.

O preâmbulo da Carta Mater (1891) afirma que a Constituinte foi organizada em um regime livre e democrático. Questiona-se então: a Carta de 1891 assevera que a Constituinte (Assembléia dos Deputados e Senadores) fora democrática; contudo, como ser possível, se as mulheres, praticamente metade da população, não votavam? Ora, se houve democracia, ao menos no plano jurídico-formal, emerge um pressuposto elástico de se estender a democracia para a seara dos Direitos Políticos. Não existe meia democracia, pois esta não pode ser decomposta em gênero masculino ou gênero feminino. A democracia é uma expressão que pode ser historicamente exposta como democracia instável, em processo de mudança da instabilidade à estabilidade ou ainda, denominada de democracia (direta, semidireta, participativa, deliberativa) dentre outras classificações, mas jamais ser fatiada entre pessoas do sexo masculino e feminino. Se em algum momento histórico de um determinado país ocorrer esse descolamento, duas situações surgirão: ou não há democracia, ou então a democracia que existia foi totalmente desintegrada.

Atente-se que o preâmbulo de uma Constituição Federal, apesar de funcionar nos limites da política e não do jurídico deve ser visto como uma intenção de princípios de Estado. Se fosse "letra morta" não deveria fazer parte da Constituição, pois uma Carta Mater tecnicamente não deve conter partes que não apresentam funcionalidade ou efetividade jurídica. Assim, reitera-se que a democracia prevista no preâmbulo da Constituição Federal de 1891 deverá ser perseguida pelos intérpretes, julgadores e defensoras(es) das lutas feministas.

Atente-se agora ao que dispõe os Arts. 69 e 70 da Constituição Federal de 1891, ipsis litteris ${ }^{6}$ :

Art. 69. São cidadãos brasileiros:

$1^{\circ}$ Os nascidos no Brasil, ainda que de pai estrangeiro, não residindo este a serviço de sua nação;

$2^{\circ}$ Os filhos de pai brazileiro e os illegitimos de mãi brazileira, nascidos em paiz estrangeiro, si estabelecerem domicilio na Republica;

$3^{\circ}$ Os filhos de pai brazileiro, que estiver noutro paiz ao serviço da Republica, embora nella não venha domiciliar-se;

$4^{\circ}$ Os estrangeiros que, achando-se no Brasil aos 15 de novembro de 1889 , não declararem, dentro em seis mezes depois de entrar em vigor a Constituição, o animo de conservar a nacionalidade de origem;

$5^{\circ}$ Os estrangeiros, que possuirem bens immoveis no Brazil, e forem casados com brazileiras ou tiverem filhos brazileiros, comtanto que residam no Brazil, salvo si manifestarem a intenção de não mudar de nacionalidade;

$6^{\circ}$ os estrangeiros por outro modo naturalisados.

Art. 70. São eleitores os cidadãos maiores de 21 annos, que se alistarem na fórma da lei.

$\S 1^{\circ}$ Não podem alistar-se eleitores para as eleições federaes, ou para as dos Estados:

$1^{\circ}$ Os mendigos;

$2^{\circ}$ Os analphabetos;

$3^{\circ}$ Os praças de pret, exceptuados os alumnos das escolas militares de ensino superior;

$4^{\circ}$ Os religiosos de ordens monásticas, companhias, congregações, ou communidades de qualquer denominação, sujeitas a voto de obediencia, regra, ou estatuto, que importe e renuncia da liberdade individual. 
$\S 2^{\circ}$ São inelegiveis os cidadãos não alistaveis. (BRASIL apud Constituição Federal,1891, p. 586-587).

Via hermenêutica jurídico-compreensiva, apreende-se que uma constituição é sistêmica, e dispõe de um conjunto de partes que forma o todo. O preâmbulo, por sua vez, funciona como princípio diretor das demais componentes, pois o constituinte o inseriu no contexto da Carta Mater com a finalidade de respeitar seu comando, mesmo não sendo uma dimensão jurídica, e sim política, ideológica e filosófica. O intérprete e/ou julgador da Constituição Federal de 1981 deveria respeitar o pressuposto do preâmbulo, denominado pelo legislador constituinte de democrático. Depois de acolher esse pressuposto, aí se debruçaria no Título IV, "Das Qualidades do Cidadão Brasileiro".

O procedimento mostrado era imprescindível para que se alcançasse o sentido da Carta Mater. A interpretação constitucional deveria ser extensiva, em face da exigência democrática contida no preâmbulo constitucional.

De plano, uma interpretação extensiva ao se deparar com o caput do Art. 69 que textualmente descreve, "são cidadãos brasileiros (...) os nascidos no Brasil, ainda que de pai estrangeiro, não residindo este a serviço de sua nação", combinado com o Art. 70 que diz "são eleitores os cidadãos maiores de 21 anos" (...), exigiria do intérprete-julgador os seguintes questionamentos, no que tange ao direito do voto feminino. Quais mulheres brasileiras se encontravam nestas situações? Afora essas exigências, existiam outras condições impostas pela Constituição Federal de 1981 que aparentemente vedavam a participação feminina ao sufrágio? Como os Parlamentares e a Justiça Eleitoral interpretavam a matéria?

De acordo com as Séries Estatísticas e Séries Históricas do IBGE (1900), somente nove anos após a promulgação da Carta Federal de 1891, tínhamos no Brasil uma população feminina equivalente a 48,96\% e no ano anterior ao Texto promulgado, 1890 de 49,50\%. Ora, o percentual de mulheres nessa época era praticamente metade da população masculina. Por outro lado, a Constituição de 1891, conforme o Art. 70, $\S 2^{\circ}, 2^{\circ}$, não permitia que analfabetos votassem. Atente-se que em 1890 tínhamos no país uma população feminina analfabeta correspondente ao percentual de 89,6\%, e em 1920 de 80,1\% (BRASIL, Diretoria Geral de Estatística, Recenseamento do Brasil, 1872 e 1920) (apud, HARNER, 2003, p. 75). Observe-se que esse contingente feminino não votava, uma vez que o Texto em alusão vedava terminantemente os analfabetos de exercerem esse direito fundamental. Do ponto de vista do direito positivo, até se aceita que o percentual feminino analfabeto não votasse, daí estender essa proibição ao contingente de mulheres nascidas no Brasil, maior de 21 anos e alfabetizadas, foi um equívoco de interpretação.

O preâmbulo constitucional exigia postura "democrática"; enquanto que o Art. 69 se expressava por meio do termo "cidadãos brasileiros"; por sua vez, o Art. 70, primeira parte, dizia, são "eleitores brasileiros os cidadãos brasileiros maiores de 21 anos"(...). Contudo, a segunda parte do Art. 70 enfatizava que os cidadãos eleitores deveriam se alistar de acordo com a lei, qual seja, uma lei federal. Ora, a objeção ao equívoco da interpretação não deve ser analisada a partir da segunda parte do caput do Art. 70, mas sim desde o preâmbulo da Constituição, que já se exigia uma postura democrática de intérpretes e/ou julgadores. Depois de ultrapassada essa exigência, aí se valendo do processo hermenêutico, analisaria o termo "cidadão", no contexto da frase da abertura do Título IV, "Das Qualidades do Cidadão Brasileiro". Neste instante é oportuna a seguinte indagação: Qual deveria ser a interpretação constitucional mais justa?

Acostando-se aos elementos históricos, filológicos, sistêmicos e teleológicos do processo hermenêutico, que funcionam como dimensões que aclaram e pacificam conflitos, 
pode-se inferir que o termo cidadão deveria ser interpretado de forma extensiva. Primeiro, porque o preâmbulo exigia postura democrática dos intérpretes e julgadores, e segundo, para que o termo cidadão ficasse em sintonia com o comando maior, que advogava pelo princípio da democracia, impunha ao intérprete e/ou julgador a compreensão e o deferimento do voto ao universo das mulheres brasileiras que ao mesmo tempo, atingiram a idade de 21 anos e foram alfabetizadas.

A Constituição de1891 não dizia textualmente que as mulheres não podiam votar. Afirmava sim, que só podiam votar quem fosse cidadão e adicionava, a esse requisito, ter idade acima de 21 anos e ser alfabetizado. O Texto não permitia, contudo, que as mulheres se alistassem, alegando que para tal intento teria que ser produzido uma lei. Ora, nestes termos a Constituição teria estabelecido um paradoxo, pois, como introduzir a democracia (exigida no preâmbulo) excluindo parte do universo humano do sufrágio brasileiro.

Mesmo assim, Juvenal Lamartine, incentivado por feministas, ao interpretar a Constituição de 1891, no Art. 70, descobre que as mulheres não estavam impedidas da prestação voluntária do serviço militar, e por essa brecha articulou os parlamentares do seu Estado, o Rio Grande do Norte, no sentido de aprovar uma lei estadual que garantisse do direito do voto às mulheres. Telles (apud, SOW, 2009) ao se debruçar sobre o fato, em um trabalho monográfico, assim se externou:

Percebe-se aqui a exigência da prestação de serviço militar que para as mulheres da época era classificado como voluntário, assim deu uma lacuna na qual não se negava o direito nem o facultava ao público feminino o acesso ao voto. $O$ que realmente exigia-se era um ato normativo que estabelecesse essa condição de voto para as mulheres, o que fez com que o presidente da Província (cargo equivalente ao governador do estado de hoje), Juvenal Lamartine, fizesse passar uma lei que permitia o direito de voto às mulheres. Em 1927 registraram-se as primeiras eleitoras de lá e, em abril de 1928, 15 mulheres votaram no Rio Grande do Norte (SOW, 2009, p. 17).

Apesar de Lamartine aprovar a lei que garantiu o voto feminino, a interpretação restritiva dos parlamentares do Senado Federal desconsiderou o processo eleitoral realizado no Rio Grande do Norte e anulou as eleições, sob a alegação de que não poderia permitir o sufrágio por meio de lei estadual, mas, via lei federal.

Mais uma vez se percebe a manobra dissimulada por parlamentares congressuais e chancelada por membros da Justiça Eleitoral da época, com o intuito de impedir o direito do sufrágio às mulheres. Observe-se que os parlamentares e/ou julgadores de antemão já desrespeitavam o preâmbulo constitucional que comungava com a democracia; agora, ao invés de interpretar o Texto extensivamente, o restringe, desfigurando princípios basilares do Direito, sob a ótica de um moralismo insustentável. A Constituição deveria neste caso ser auto-aplicável sem a necessidade de se exigir o alistamento feminino, pelo simples fato das mulheres estarem inclusas no amplo conceito de "cidadãos" e reforçarem o processo da afirmação da democracia no Brasil.

\section{Direito e Federação Brasileira para o Progresso Feminino}

Após a exposição do processo hermenêutico, por intermédio da interpretação extensiva, mostrar-se-á como o Direito desloca-se no tempo e no espaço, interagindo com a vertente do feminismo bem comportado, e como ambos, de forma sinérgica, contribuem para a aceitação do sufrágio das mulheres. 
Eis o momento de perguntar: como foi criada a Federação Brasileira para o Progresso Feminino? Quais os caracteres mais significativos do seu aparecimento? Quais as relações ocorrentes entre o Direito e a Federação?

De plano, levanta-se aqui uma preliminar: o que quer dizer federação? "Do latim foederatio, de foederare (unir, legar por aliança), é empregado na técnica do Direito Público" (...). (SILVA, 2006, p. 606). A federação permitia que as feministas, quer dizer, a vertente bem comportada do feminismo, se fortalecesse como organização e acelerasse sua escalada rumo ao sufrágio.

O processo federativo dessas mulheres ancorava-se em dois pressupostos: o positivismo e o progresso.

O positivismo caracteriza-se como corrente filosófico-político-social e em seu percurso sofre influencia do cientificismo. Segue fielmente os ditames do conhecimento científico e o método de observação.

O progresso, conforme redação, pode ser compreendido

Como idéia de que o curso das coisas, especialmente da civilização, conta desde o início com um gradual crescimento de bem-estar ou da felicidade, com uma melhora do indivíduo e da humanidade, constituindo um movimento em direção a um objeto desejável. A idéia de um universo em perpétuo fluxo na basta, pois, para formar a idéia de Progresso; é necessária também uma finalidade, um objetivo último do movimento. É na concretização deste objetivo último que se acha a medida do Progresso. É por isso que se fala de 'fé no Progresso (BOBBIO, 1999, p. 1009-1010).

Antes da Federação Brasileira para o Progresso Feminino - FBPF - ser criada já existia uma Liga para Emancipação Intelectual da Mulher, fundada em 1920, por Bertha Lutz $^{7}$ e Maria Lacerda de Moura ${ }^{8}$. Outras feministas também contribuíram, direta ou indiretamente, para a criação da FBPF, fora do eixo Sudeste (São Paulo, Minas Gerais e Rio de Janeiro). Exemplos marcantes dessas lutas se encontram registrados nos jornais da época, no Nordeste em Rio Grande do Norte, Paraíba, Pernambuco e Bahia, além de lutas no Sul (em especial no Rio Grande do Sul).

A FBPF, tomando como base o positivismo-progressista e orientada por seus estatutos, apresenta no Art. $3^{\circ}$ os seguintes objetivos: 1 . Promover a educação da mulher e elevar o nível de instrução feminina. 2. Proteger as mães e a infância. 3. Obter garantias legislativas e práticas para o trabalho feminino. 4. Auxiliar as boas iniciativas da mulher e orientá-la na escolha da profissão. 5. Estimular o espírito de sociabilidade e de cooperação entre as mulheres e interessá-las pelas questões sociais e de alcance público. 6. Assegurar à mulher os direitos políticos que a nossa Constituição lhe confere e prepará-la para o exercício inteligente desses direitos. 7. Estreitar os laços de amizade com os demais países americanos, a fim de garantir a manutenção perpétua da Paz e da Justiça no Hemisfério Ocidental.

Pergunta-se: qual o significado da palavra Objetivo?

Diz-se do que é válido para todos, e não apenas para um indivíduo. Dizse de fenômeno natural que se determina conforme os critérios científicos vigentes. (...) No método interativo, o valor final para o qual convergem progressivamente os resultados das sucessões de interações (NOVO DICIONÁRIO AURÉLIO, 1999, p. 1427). 
Nem todos os objetivos propostos pela FBPF foram alcançados, todavia, serviram como marco de lutas femininas futuras, sobretudo no campo do direito do voto das mulheres.

Eis o momento de esclarecer a participação do Direito na FBPF. Ao formular seus estatutos e traçarem objetivos, as feministas diretamente atrelam-se ao campo jurídico, tanto pelo prisma legal quanto da legitimidade. Mas qual é o sentido do termo Estatuto?

Derivado do latim statutum, de statuere (estabelecer, construir, fundar), em sentido amplo, entende-se a lei ou regulamento, em que se fixam os princípios institucionais ou orgânicos de uma coletividade ou corporação, pública ou particular (privada). Em qualquer aspecto ou sentido, pois, o estatuto geralmente dito no plural estatutos, exibe o complexo de normas ou regras (...) (SILVA, 2006, p. 559-560).

Diante do conceito alargado do termo estatuto, percebe-se que os aspectos normativos vão se configurando com mais vigor na proposta planejada pela vertente feminista bem comportada. É interessante comentar que o Direito, especialmente o positivado, se apresenta no cenário social, mais das vezes por intermédio de estatutos e objetivos.

A FBPF, talvez percebendo que apenas se valendo do Direito histórico não alcançaria seu desiderato, lançou mão da outra face do Direito, qual seja, o Direito positivo. A FBPF não apreendeu o Direito positivo de forma dissimulada, ao contrário, concebia-o como meio de alcance ao sufrágio feminino. Em resumo, qual era o real intento da FBPF? Lógico que era o direito do voto feminino e não a emancipação plena da mulher. Assim, bastaria se valer das suas lutas, estratégias e do direito em seu duplo movimento (histórico e positivo) que galgaria sua finalidade máxima: o sufrágio para todas as mulheres que se encontravam nas condições descritas no Texto Constitucional: ser brasileira, ter 21 anos e ser alfabetizadas, sem mais nenhuma exigência legal-condicional.

Observe-se que de antemão, no preceito número 1 dos objetivos, se exigiu ampliar a educação feminina, pois era condição sine qua non para o êxito da Federação. Outro preceito que merece destaque, o de número 6, que visava assegurar à mulher os direitos políticos que a Constituição de 1891 lhe conferia. Mais uma vez se percebe os laços de união entre a FBPF e o Direito. Observa-se ainda a nitidez que essa vertente feminista tinha acerca dos seus direitos constitucionais, pois nos seus objetivos não adentrara no tema do alistamento feminino. Deduz-se, então, que a interpretação dessa vertente não era diminuta acerca da emancipação da mulher, contudo, não fazia parte do seu planejamento ir além da luta pelo sufrágio feminino, para não correr o risco de se desviar por demais da sua luta específica, parcial, porém não insignificante naquele momento histórico.

A FBPF se reduziu apenas a um marco cronológico nas lutas feministas? Em um país marcado por colonização, escravidão e preconceitos, bem como apenas utilizando as dimensões da educação e da imprensa, a FBPF teria fôlego para galgar a emancipação feminina em sua totalidade?

É difícil responder aos questionamentos propostos. Que fique bem claro, não alcançar o total do processo de emancipação da mulher não significa obrigatoriamente abdicar das lutas, lutas que muitas vezes acontecem em etapas, ladeando com ondular da política e da história. Uma guerra (as lutas feministas) é vencida por batalhas, às vezes nas trincheiras (as estratégias), às vezes se valendo das armas dos adversários (o Direito positivo da época).

Isso tudo representa o caminhar árduo da FBPF, que muitas vezes é vilipendiada tanto por homens quanto por algumas mulheres. As diatribes sofridas talvez sirvam de combustível para a "história da educação" lançar um olhar mais aprofundado sobre a 
organização que não foi além do previamente planejado e como teleologia alcançou resultados se não excelentes ao processo de emancipação feminina, ao menos obteve resultados ao longo dos anos, no campo dos Direitos Políticos, especificamente no sufrágio feminino (capacidade eleitoral ativa - direito de votar e capacidade eleitoral passiva direito de ser votada, no futuro).

A FBPF atingiu seu apogeu não com o Código Eleitoral Provisório e o Decreto $\mathrm{n}^{\circ}$. 21.076, de 24 de fevereiro de 1932, uma vez que o direito de votar era restrito, pois as mulheres casadas só votariam com a permissão do esposo, e as viúvas e solteiras se possuíssem renda própria. Somente com a promulgação da Constituição Federal de 1934 e sua antecessora e produtora, a Constituinte, se consolidou o direito do voto feminino no Brasil. Após alcançar o ponto máximo da luta a FBPF começa, a partir de então, se arrefecer e vai perdendo força no cenário nacional. Longe da redundância, lembre-se que a FBPF não foi apenas um marco ao longo do processo de lutas feministas, ao contrário, conseguiu o seu objetivo maior, permitir que as mulheres brasileiras pudessem votar e serem votadas.

\section{Conclusão}

A História é uma expressão ampla que comporta tensões, estratégias e articulações em torno de dimensões conflitantes. A política, o Direito, a educação e a imprensa são dimensões que atuam em arenas movimentando-se no fluxo e refluxo de suas teorias e argumentações. As feministas da vertente bem comportada absorveram elementos dessas dimensões e descartaram estrategicamente parte de informações que eram entraves ao seu intento.

Sem embargo do exposto, a FBPF despiu-se de preconceitos e assumiu sua real identidade, captando com muita ênfase em suas lutas os seguintes tópicos: 1. Como pressupostos filosóficos, políticos e sociais - o positivismo e o progresso. 2. Como estratégias de lutas - a educação e a imprensa. 3. Como meio de alcance do sufrágio feminino - o Direito em seu duplo movimento (histórico e positivo).

À guisa de conclusão, a História permitiu mostrar que a vertente do movimento feminista bem comportado se agarrou a várias dimensões sem se preocupar com suas inevitáveis colisões. Quando necessário e/ou imprescindível se articulou e, por meio de sutileza e perspicácia, engendrou quase um sistema que se perfez por intermédio interativo da Política, do Direito, da Educação e da Imprensa rumo ao sufrágio feminino.

\section{Referências}

BOBBIO, Noberto; MATTEUCI, Nicola; PASQUINO, Gianfranco. Dicionário de política. (Trad.) Carmen C. Varriali et al. 12 ed. Brasília: Editora Universidade de Brasília, 1999.

BRASIL. Constituições do Brasil (1969;1967;1946;1937;1934;1891;1824). 6 ed. São Paulo: Atlas, 1983.

FERREIRA, Aurélio Buarque de Holanda. Novo Aurélio século XXI: o dicionário da língua portuguesa. 3 ed. Rio de Janeiro: Nova Fronteira, 1999.

GRAU, Eros Roberto. O direito posto e o direito pressuposto. São Paulo: Malheiros Editores, 1996. 
HAHNER, June E. A mulher brasileira e suas lutas sociais e políticas (1850-1937). (Trad.) Maria Thereza P. de Almeida e Heitor Ferreira da Costa. São Paulo: Editora Brasiliense, 1981.

Emancipação do sexo feminino: a luta pelos direitos da mulher no Brasil, 1850-1940. (Trad.) Eliane Tejera Lisboa. Florianópolis: Ed. Mulheres/EDUNISC, 2003.

IBGE. SÉRIES ESTATÍSTICAS E SÉRIES HISTÓRICAS. Disponível em: <www.ibge.gov.br/seiries_estatisticas>. Acesso em: Acesso em: 11 de set. 2010.

IHERING, Rudolf Von. A luta pelo direito. (Trad.) João de Vasconcelos. 18 ed. Rio de Janeiro: Forense, 1999.

MONTAGU, Ashley. A superioridade natural da mulher. (Trad.) Lygia Junqueira Caiuby. Rio de Janeiro: Editora Civilização Brasileira, 1970.

PERROT, Michelle. Minha história das mulheres. (Trad.) Ângela M. S. Corrêa. São Paulo: Editora Contexto, 2008.

PINTO, Céli Regina Jardim. Uma história do feminismo no Brasil. São Paulo: Editora Fundação Perseu Abramo, 2003.

REALE, Miguel. Filosofia do direito. 17 ed. São Paulo: Saraiva, 1996.

RODRIGUES, João Batista Cascudo. A mulher brasileira: direitos políticos e civis. 3 ed. Brasília: Centro Gráfico do Senado Federal, 1993.

SILVA, De Plácido e. Dicionário Jurídico. 26 ed. Rio de Janeiro: Forense, 2006.

SOW, Marilene Mendes. A participação feminina na construção de um parlamento democrático. Brasília: Biblioteca da Câmara dos Deputados, 2009.

TABAK, Fanny; TOSCANO, Moema. Mulher e política. Editora Paz e Terra, 1982.

Notas

\footnotetext{
${ }^{1}$ Artigo Científico desenvolvido como parte do Estágio Pós-Doutoral no Programa de Pós-Graduação em Educação da Universidade Federal da Paraíba - UFPB - na Linha de História da Educação.

${ }^{2}$ Professor Doutor, Orientador (Mestrado e Doutorado) da Universidade Federal de Campina Grande UFCG.

${ }^{3}$ Professor Doutor, Orientador (Mestrado e Doutorado) no Programa em Educação da Universidade Federal da Paraíba - UFPB - e Supervisor do Estágio Pós-Doutoral na Linha de Pesquisa de História da Educação.

${ }^{4}$ Ver obra de TABAK, Fanny; TOSCANO, Moema. Mulher e Política, p. 90.

${ }^{5}$ Mulheres como Mirtes Campos (primeira mulher admitida na advocacia brasileira), já pressionavam pelo voto feminino por intermédio da imprensa e da Associação de Advogados (mais tarde, Ordem dos Advogados do Brasil. In: HAHNER, June E. Emancipação do sexo feminino: a luta pelos direitos da mulher no Brasil 1850-1940.

${ }^{6}$ Nesta citação optou-se por manter a grafia da Constituição Federal de 1891 na forma original em que fora redigida.

${ }^{7}$ Oriunda da elite brasileira, formada em Biologia na Universidade Sorbonne, tempo depois se formou em Direito. Representou o Brasil na I Conferência Pan-Americana da Mulher nos Estados Unidos da América e no Conselho Feminino da Organização Internacional do Trabalho. Defensora da luta pelo direito do voto feminino, no molde norte-americano.

${ }^{8}$ Escritora, professora, que colocava suas estratégias no poder da imprensa para arregimentar seguidoras ao alcance da emancipação da mulher.
}

Recebido em: $\quad$ 17/04/11

Aprovado em: $22 / 08 / 11$ 